\section{RMD Open}

Rheumatic \&

Musculoskeletal Diseases

\title{
Prevalence and incidence of gout in southern Sweden from the socioeconomic perspective
}

\author{
Meliha C Kapetanovic, ${ }^{1}$ Mohaned Hameed, ${ }^{1}$ Aleksandra Turkiewicz, ${ }^{2}$ \\ Tuhina Neogi, ${ }^{3}$ Tore Saxne,${ }^{1}$ Lennart Jacobsson, ${ }^{4}$ Martin Englund ${ }^{2,3}$
}

To cite: Kapetanovic MC, Hameed M, Turkiewicz A, et al. Prevalence and incidence of gout in southern Sweden from the socioeconomic perspective. RMD Open 2016;2:e000326. doi:10.1136/rmdopen-2016000326

- Prepublication history and additional material is available. To view please visit the journal (http://dx.doi.org/ 10.1136/rmdopen-2016000326)

Received 4 July 2016 Revised 4 September 2016 Accepted 7 September 2016

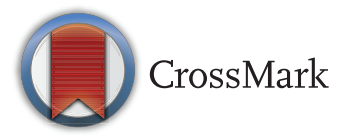

For numbered affiliations see end of article.

\section{Correspondence to} Dr Meliha C Kapetanovic; meliha.c_kapetanovic@med. lu.se

\section{ABSTRACT}

Objectives: To estimate the prevalence and cumulative incidence of gout in southern Sweden with respect to socioeconomic status.

Methods: Among residents of Skåne region in the year 2013 (total population 1.3 million), adult persons (age 18 years + ) who between 1998 and 2013 received a diagnosis of gout (International Classification of Disease 10th Edition (ICD-10) code M10) by any physician were identified using the Skåne Healthcare Register. We calculated the point prevalence by end of 2013 and annual cumulative incidence in 2013 standardised to the whole Skåne population according to sex, individual information on occupation (white collar/blue collar), income (low/middle/high) and level of education (primary school/high school/university).

Results: The crude 2013 point prevalence of gout and 2013 cumulative incidence $(95 \% \mathrm{Cl})$ were $1.69 \%$ $(1.66 \%$ to $1.71 \%)$ and 24 cases per 10000 persons (23-25), respectively. Compared to women, men had higher point prevalence $(2.44 \%(2.40 \%$ to $2.49 \%)$ vs $0.96 \%(0.93 \%$ to $0.98 \%))$ and higher annual cumulative incidence (33 cases per 10000 (32-35)) versus 15 (14-16)). These figures increased with higher age but decreased with higher level of education, being the lowest in individuals with a university degree. Persons with middle income had highest point prevalence and cumulative incidence of gout, while those with white collar occupations had the lowest.

Conclusions: Gout is the most common inflammatory arthritis in southern Sweden with a prevalence of $\sim 1.7 \%$ in the adult population. There is a socioeconomic gradient with more gout present in the lower level of education and with more manual labour.

\section{INTRODUCTION}

Gout is the most common inflammatory arthritis in men and in the elderly. ${ }^{1-9}$ Several studies have reported an increasing prevalence and incidence of gout worldwide. ${ }^{1-4}$ However, there is a wide range of estimates depending on, for example, age and sex of

\section{Key messages}

Gout is the most common inflammatory arthritis in southern Sweden affecting $\sim 1.7 \%$ of the adult population.

- There is a relationship between prevalent and incident gout and socioeconomic status.

- Gout is more present in individuals with lower the level of education and with more manual labour.

- There is room for improvement through better education, increasing awareness of risk factors and encouraging a healthier lifestyle.

study population, geographic region, definition of gout or other methodological differences between studies. ${ }^{1-3}$ Male sex is a well-recognised risk factor for gout, whereas females are relatively protected in the premenopausal stage of life. ${ }^{1-13}$ The prevalence of gout increases with age, most likely related to other risk factors that also increase with age such as hypertension and associated diuretic treatment, obesity and other metabolic and renal diseases. ${ }^{1-4} 78$ A study on prevalence of gout and associated comorbidities among all living residents in Stockholm County, Sweden (population of about 2100000 people) identified $0.3 \%$ women and $0.9 \%$ men with gout in 2013-2014. Compared to individuals without gout, alcohol abuse was overrepresented among gout cases and hypertension was the most prevalent comorbidity. ${ }^{9}$

Insights regarding the association between gout and the socioeconomic status derive primarily from older studies. Historically, gout was primarily considered as the 'disease of kings', attributable to lifestyle factors affordable only by rich people. Over time, more food and new food choices have been available and affordable for far more people. Chronic overconsumption of food, alcohol and fructose sweetened soft drinks in 
combination with a sedentary lifestyle has resulted in increased prevalence of visceral obesity and metabolic syndrome in groups with lower socioeconomic levels (RN Beyl Jr, L Hughes, S Morgan. Update on importance of diet in gout. Am J Med 2016). Patients with gout have a high prevalence of metabolic syndrome. ${ }^{14}$ In a study from 1982 conducted in three English towns, an inverse relation between socioeconomic status and prevalence of gout was found. ${ }^{5}$ In a cross-sectional observational study on the association of gout with socioeconomic status in primary care in the UK, gout was also more common in individuals with low income. ${ }^{6}$ In another study from the USA, the investigators reported gout being more common among African-Americans and those having low income. ${ }^{7}$ These data suggest that there is a need of primary prevention with, for example, education, increasing awareness of risk factors and encouraging healthier lifestyle and that this need may be largest in the lower socioeconomic group. So far, there is no study investigating the association between socioeconomic factors and prevalence or incidence of gout in Sweden.

The purpose of the present study was to estimate the prevalence and cumulative incidence of gout among adult residents of Skåne region in southern Sweden. In addition, we also wanted to explore whether socioeconomic status, including current occupation, income and level of education, was associated with the prevalence and incidence of gout.

\section{METHODS}

\section{Data sources}

Data on age, sex and residential area were retrieved from the national Swedish population register. The Skåne Healthcare Register (SHR) contains data on visits to any physician including up to eight diagnosis codes between 1998 and 2013. The diagnoses are registered using the International Classification of Diseases 10th Edition (ICD-10) system. Diagnostic codes from private care, which are responsible for around 30\% of all physician visits within primary care, are not forwarded to the SHR. Statistics Sweden provided individual data on occupation, education and income in the year 2013. Data on individual level of medication use between 1 July 2005 and 31 December 2011 were retrieved from the Swedish Prescribed Drug Register. All information retrieved was linked on an individual level using the Swedish 10-digit personal identification number.

\section{Definition of gout}

A person has been considered as having gout if any M10 diagnostic code according to the ICD-10 had been registered 'at least once' by any physician (within primary or secondary care). The date when the criterion was first fulfilled was considered as the date of gout diagnosis.

\section{Outcome measures}

The 2013 point prevalence was defined as the proportion of all participants $\geq 18$ years, still residents of Skåne region as on 31 December 2013 having fulfilled our gout definition between 1 January 1998 and 31 December 2013.

We calculated the cumulative incidence as the proportion of all participants $\geq 18$ years, who were residents of Skåne region by 31 December 2012, fulfilling our gout criterion between 1 January 2013 and 31 December 2013 among those with no physician-diagnosed gout in the region between 1 January 1998 and 31 December 2012.

We calculated both crude and standardised estimates (direct method) using the whole Skåne population aged $\geq 18$ years as standard population.

\section{Socioeconomic status}

Occupation was categorised using a Swedish standard system for classification of occupations (Standard för Svensk Yrkes Klassificering 1996; SSYK96) ${ }^{15}$ based on the International Standard Classification of Occupations (ISCO-88). ${ }^{16}$ The following groups of occupations were identified: high skilled white collar (managers, professionals and technicians and associated professionals), low skilled white collar (clerical support workers and service and sales workers), high skilled blue collar (skilled agricultural, forestry and fishery workers and craft and related trades workers) and low skilled blue collar (plant and machine operators, and assemblers and occupations with demand of elementary education) while the military was excluded due to the limited number of individuals in this category. The occupation was available for $72 \%$ of the included population.

Level of education was stratified in the following categories: 0-9 years (primary school), 10-12 years (high school), 13-14 years (upper secondary school) and $\geq 15$ years (university degree). We categorised income into three groups: lowest quartile (low income), 2nd and 3rd quartiles (middle income) and highest quartile (high income). The complete data on education and income were available for $95 \%$ of the participants.

\section{Validity of the gout diagnosis}

Allopurinol is the most commonly used drug for gout and it is recommended as a first-line urate lowering therapy. ${ }^{12}{ }^{13}$ In order to validate the gout diagnoses, we used the Swedish Prescribed Drug Register and retrieved data on all prescriptions of allopurinol, that is, M04A code according to the Anatomical Therapeutic Chemical classification system that resulted in delivery of the drug to the patient in any pharmacy in Sweden between July 2005 and December 2011. The ATC codes registered in the Prescribed Drug register in the M04A group were: M04AA01 (allopurinol), M04AB01 (probenecid) and M04AC01 (colchicine) where allopurinol accounted for $97 \%$ of all issued medications.

For 2011 incident gout cases, we checked the proportion with allopurinol prescription at any time during 2011 while for 2011 prevalent cases, the proportion with prescription using all available drug data was calculated. 
In addition, we calculated how many of the allopurinol users in 2011 fulfilled the gout definition for being either incident or prevalent for gout in 2011.

\section{Sensitivity analysis}

We estimated the prevalence and incidence of gout using an alternative, more stringent gout definition. A person has been considered as having gout if any M10 diagnostic code according to the ICD-10 has been registered at least once by a physician within secondary care (internal medicine or rheumatology) or at least twice by any other physician (within general practice or other specialties in secondary care). The date when the criterion was first fulfilled (ie, the date of the second visit if applying the second criterion) was considered as the date of gout diagnosis.

The ethical approval (Dnr 2014/276) mandatory for this study was obtained from Regional Ethical Review Board at Lund University, Lund, Sweden.

\section{RESULTS}

The 2013 point prevalence of gout and annual cumulative incidence $(95 \%$ CI) among adult residents of Skåne region in 2013 were $1.69 \%$ (1.66\% to $1.71 \%)$ and $24^{23-25}$ cases per 10000 persons, respectively. After performing age and sex standardisation to the whole adult Skåne population (ie, proportions represent what would have been observed if the age and sex distribution in each group was as in the general population), the prevalence of gout was highest among individuals with a lower level of education (primary school) or middle income (table 1). The lowest prevalence was observed in individuals having high skilled white collar occupations as shown in figure 1 . The pattern was similar for incident gout.

Online supplementary file 1 shows the crude 2013 point prevalence and cumulative incidence of gout
(95\% CI). The mean (SD) age of a person with prevalent gout was 69.5 (14.1) years and of a person with incident gout 68.4 (14.6) years. Both point prevalence and cumulative incidence were higher in men $(2.44 \%$ (2.40\% to $2.49 \%)$ and 33 cases per 10000 (32-35), respectively) than in women $(0.96 \%(0.93 \%$ to $0.98 \%)$ and 15 cases per 10000 (14-16), respectively) (see online supplementary file 1 , figure 2 ).

The prevalence and the incidence of gout increased with increasing age. Among the oldest individuals (85 years and older), the prevalence was as high as $7.15 \%$. The corresponding cumulative incidence in this group was 94 cases per 10000 . Among all adults in the region, the prevalence and the incidence of gout were highest in persons with the lowest level of education (primary school), those having middle income and individuals with high skilled blue collar occupations (see online supplementary file 1 ).

The validity analysis of a gout (M10) diagnosis with respect to allopurinol prescription shows that of 14391 prevalent 2011 gout cases, $59 \%$ (8472) had at least one allopurinol prescription (delivered to a patient at a pharmacy) between July 2005 and December 2011.

Out of 2377 incident 2011 gout cases, 48\% (1137) had at least one delivered allopurinol prescription during the year 2011. Of 12663 allopurinol users in the year 2011 (in the Skåne population in 2010 or 2011), 54\% (6791) were either incident or prevalent cases in 2011.

The percentages of 2011 prevalent and incident gout cases in different socioeconomic groups (age and sex standardised to the whole gout prevalent/incident population) who received allopurinol prescriptions between 2005 and 2011 are summarised in table 2. Among 2011 prevalent gout cases, individuals with $\geq 15$ years of education had significantly lower allopurinol prescriptions compared to those of individuals with $<12$ years of

Table 1 The 2013 point prevalence and cumulative incidence of gout $(95 \% \mathrm{Cl})$, age and sex standardised to the whole Skåne population (ie, proportions represent what would have been observed if the age and sex distribution in each group was as in the general population)

\begin{tabular}{|c|c|c|c|c|}
\hline Variable & $\begin{array}{l}\text { Point } \\
\text { prevalence (\%) }\end{array}$ & $95 \% \mathrm{Cl}$ & $\begin{array}{l}\text { Cumulative incidence } \\
\text { per } 10000\end{array}$ & $95 \% \mathrm{Cl}$ \\
\hline All & 1.69 & (1.66 to 1.71$)$ & 23.8 & (22.8 to 24.8 ) \\
\hline \multicolumn{5}{|l|}{ Education (years) } \\
\hline $0-9$ & 1.99 & (1.93 to 2.04$)$ & 26.8 & (24.8 to 28.8 ) \\
\hline $10-12$ & 1.76 & (1.72 to 1.8$)$ & 25.1 & (23.5 to 26.7 ) \\
\hline $13-14$ & 1.47 & (1.39 to 1.55$)$ & 21.1 & (17.9 to 24.2$)$ \\
\hline $15+$ & 1.27 & (1.21 to 1.33 ) & 17.1 & (14.8 to 19.5$)$ \\
\hline \multicolumn{5}{|l|}{ Income } \\
\hline Low & 1.63 & (1.56 to 1.71$)$ & 21.6 & (18.9 to 24.4 ) \\
\hline Middle & 1.81 & (1.78 to 1.85$)$ & 25.0 & (23.6 to 26.3 ) \\
\hline High & 1.48 & (1.41 to 1.54$)$ & 20.8 & (18.3 to 23.2$)$ \\
\hline \multicolumn{5}{|l|}{ Occupation } \\
\hline White collar, high skilled & 1.5 & (1.45 to 1.55$)$ & 20.6 & (18.8 to 22.5$)$ \\
\hline White collar, low skilled & 1.73 & (1.65 to 1.81$)$ & 24.5 & (21.3 to 27.7$)$ \\
\hline Blue collar, high skilled & 1.71 & (1.6 to 1.81$)$ & 24.3 & (20.1 to 28.5 ) \\
\hline Blue collar, low skilled & 1.91 & (1.83 to 1.99$)$ & 25.2 & (22.1 to 28.2 ) \\
\hline
\end{tabular}



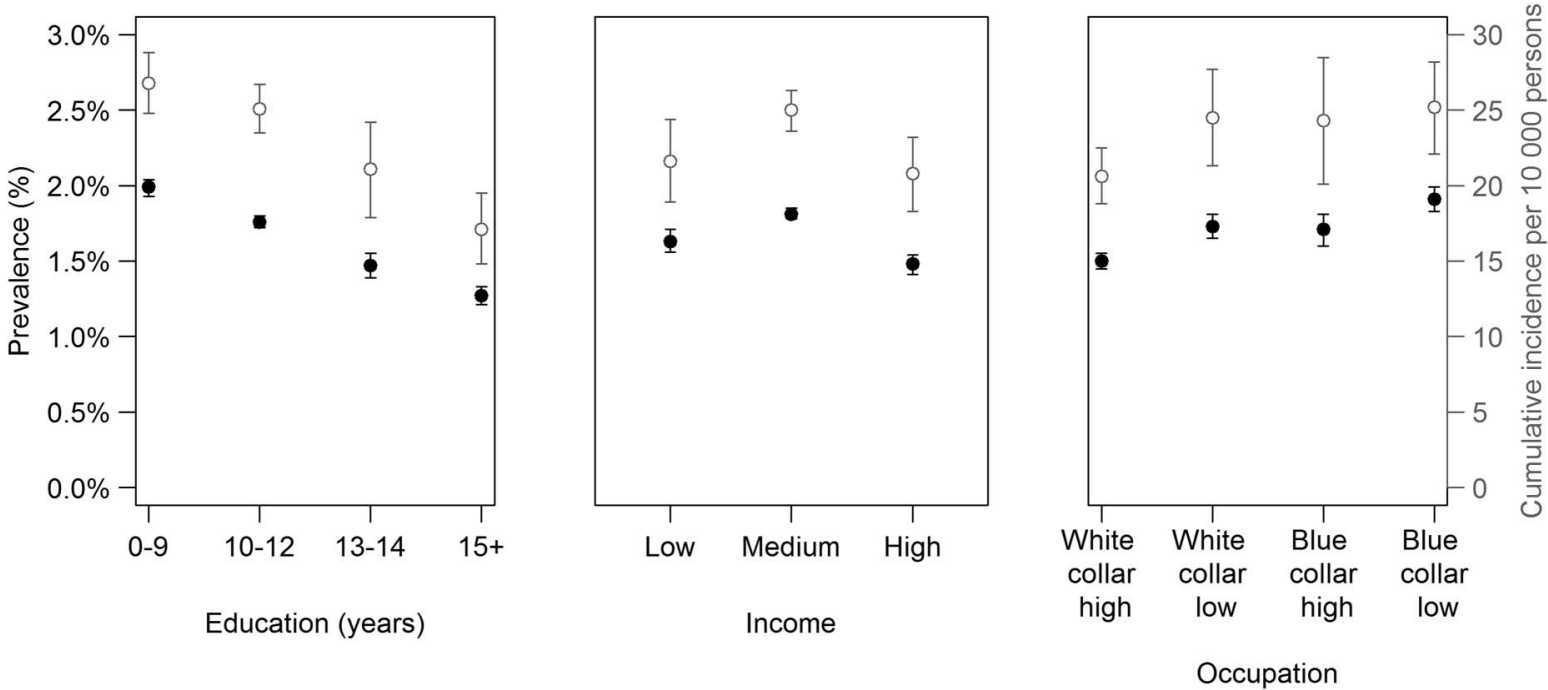

Figure 1 The 2013 point prevalence (black circles) and cumulative incidence (grey open circles) of gout with 95\% Cls by socioeconomic groups, age and sex standardised to the whole adult Skåne population.
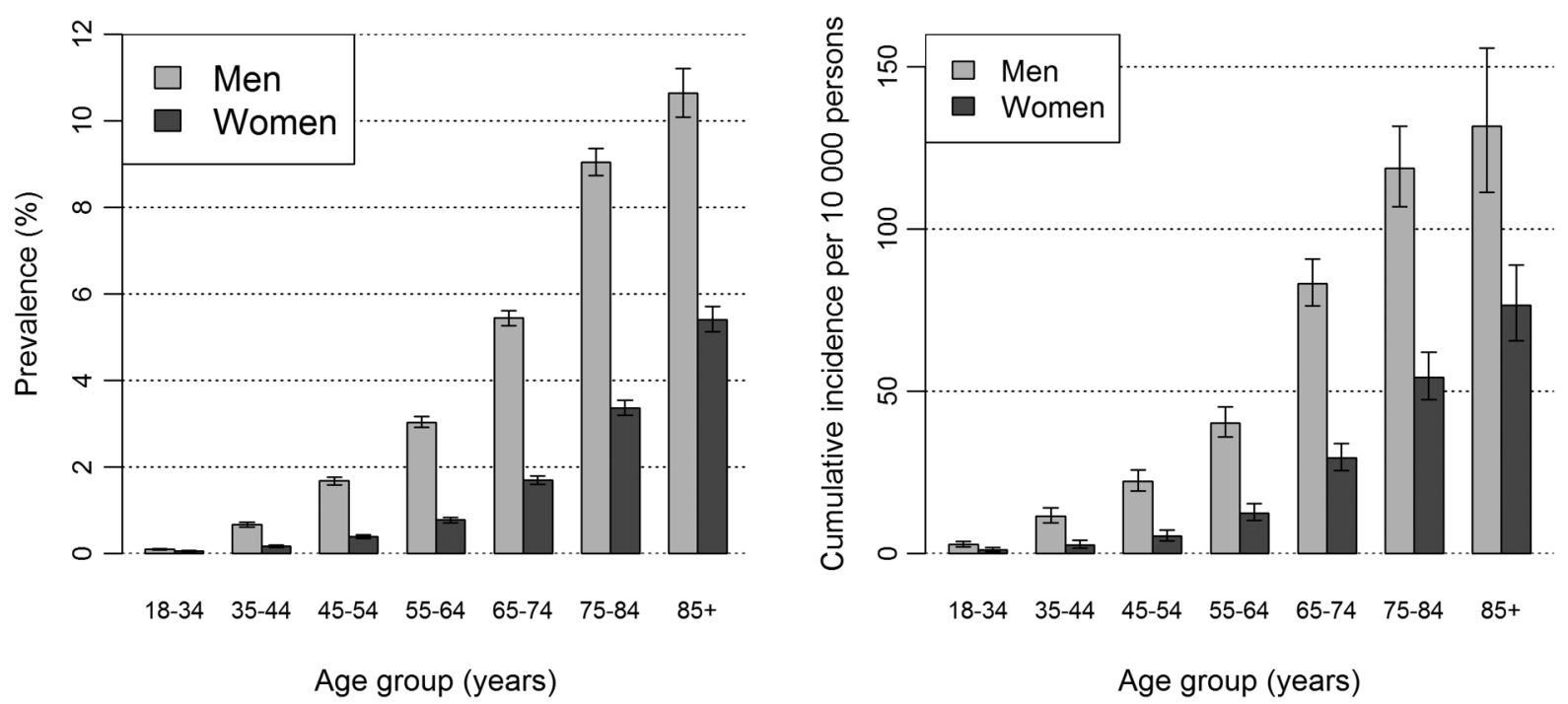

Figure 2 The 2013 point prevalence and cumulative incidence of gout with $95 \%$ Cls, by age group and sex.

education. A significantly lower percentage of allopurinol prescriptions was seen in individuals with the highest income. The highest percentage of allopurinol prescription among prevalent gout cases was found in high skilled blue collar occupations $(62 \%)$. Such differences were not seen among 2011 incident cases.

Sensitivity analysis using a more stringent definition of gout diagnosis showed lower prevalence and incidence figures $(1.05 \%$ and 18 per 10000 , respectively), but the pattern was similar (table 3). The 2013 point prevalence and cumulative incidence of gout, after age and sex standardised to the whole Skane population and after using this more stringent definition, were highest among individuals with only primary school education, middle income and blue collar low skilled occupations. Crude 2013 point prevalence and cumulative incidence of gout using a more stringent definition of gout is shown in online supplementary file 2 .

The prescriptions of allopurinol among diagnosed gout cases stratified by socioeconomic group are summarised in table 4. No large differences in prescription of allopurinol among prevalent and incident gout cases were observed with respect to level of education, income or occupation.

\section{DISCUSSION}

In this study, we investigated the occurrence of gout in Southern Sweden and highlighted the association with socioeconomic factors. We found the 2013 prevalence of gout to be $\sim 1.7 \%$ of the adult population. The annual cumulative incidence was 24 cases per 10000 adults. 
Table 2 The prescriptions of allopurinol among diagnosed gout cases by socioeconomic group

\begin{tabular}{|c|c|c|c|c|}
\hline Variable & $\begin{array}{l}\text { Per cent with } \\
\text { allopurinol prescription } \\
2005-2011 \\
\text { among } 2011 \\
\text { prevalent cases }\end{array}$ & $95 \% \mathrm{Cl}$ & $\begin{array}{l}\text { Per cent with } \\
\text { allopurinol prescription } 2011 \\
\text { among } 2011 \\
\text { incident cases }\end{array}$ & $95 \% \mathrm{Cl}$ \\
\hline All & 58.9 & (58.0 to 59.7 ) & 47.8 & (45.8 to 49.8 ) \\
\hline \multicolumn{5}{|l|}{ Education (years) } \\
\hline $0-9$ & 59.9 & (58.6 to 61.3 ) & 47.6 & (44.3 to 50.9 ) \\
\hline $10-12$ & 58.4 & (57.2 to 59.7 ) & 46.7 & (43.5 to 49.9 ) \\
\hline $13-14$ & 58.0 & (55.1 to 61.0 ) & 48.9 & (41.7 to 56.2$)$ \\
\hline $15+$ & 53.7 & (51.0 to 56.4 ) & 49.1 & (42.4 to 55.8 ) \\
\hline \multicolumn{5}{|l|}{ Income } \\
\hline Low & 61.2 & (58.7 to 63.7 ) & 54.2 & (48.2 to 60.1$)$ \\
\hline Middle & 59.8 & (58.8 to 60.8 ) & 48.0 & (45.4 to 50.5$)$ \\
\hline High & 55.6 & (53.2 to 58.0 ) & 49.3 & (43.3 to 55.3 ) \\
\hline \multicolumn{5}{|l|}{ Occupation } \\
\hline White collar, high skilled & 55.9 & (53.5 to 58.3 ) & 45.0 & (41.0 to 48.9 ) \\
\hline White collar, low skilled & 59.6 & (56.9 to 62.2 ) & 48.5 & (41.8 to 55.2$)$ \\
\hline Blue collar, high skilled & 61.7 & (58.5 to 65.0 ) & 37.0 & (30.7 to 43.2$)$ \\
\hline Blue collar, low skilled & 58.9 & (55.8 to 61.9 ) & 47.8 & (43.2 to 52.5$)$ \\
\hline
\end{tabular}

Table 3 Sensitivity analysis

\begin{tabular}{|c|c|c|c|c|}
\hline Variable & Point prevalence (\%) & $95 \% \mathrm{Cl}$ & $\begin{array}{l}\text { Cumulative incidence } \\
\text { per } 10000\end{array}$ & $95 \% \mathrm{Cl}$ \\
\hline All & 1.05 & (1.03 to 1.07 ) & 17.7 & (16.9 to 18.6 ) \\
\hline \multicolumn{5}{|c|}{ Education (years) } \\
\hline $0-9$ & 1.24 & (1.20 to 1.28$)$ & 19.0 & (17.4 to 20.6 ) \\
\hline $10-12$ & 1.09 & (1.06 to 1.12$)$ & 19.0 & (17.6 to 20.4 ) \\
\hline $13-14$ & 0.91 & (0.85 to 0.97 ) & 14.4 & (11.8 to 17.0$)$ \\
\hline $15+$ & 0.75 & (0.70 to 0.79$)$ & 13.3 & (11.2 to 15.4 ) \\
\hline \multicolumn{5}{|l|}{ Income } \\
\hline Low & 1.04 & (0.98 to 1.10$)$ & 18.4 & (15.8 to 21.0 ) \\
\hline Middle & 1.15 & (1.12 to 1.18$)$ & 18.8 & (17.6 to 19.9 ) \\
\hline High & 0.85 & (0.80 to 0.90$)$ & 15.4 & (13.1 to 17.7$)$ \\
\hline \multicolumn{5}{|l|}{ Occupation } \\
\hline White, high & 0.92 & (0.88 to 0.96$)$ & 16.0 & (14.2 to 17.7 ) \\
\hline White, low & 1.07 & (1.01 to 1.14 ) & 18.0 & (15.3 to 20.6 ) \\
\hline Blue, high & 1.09 & (1.00 to 1.17 ) & 18.4 & (14.9 to 21.8 ) \\
\hline Blue, low & 1.17 & (1.10 to 1.23 ) & 18.9 & (16.0 to 21.8 ) \\
\hline
\end{tabular}

Both prevalence and cumulative incidence were higher in men compared to women, and they increased with increasing age. In people older than 85 years, 1 of 14 persons had been diagnosed with gout. We found lower level of education, middle-range income and high skilled blue collar occupations to be associated with increased occurrence of gout.

Affecting $2.44 \%$ of adult males and $0.96 \%$ of females, gout is the most prevalent inflammatory arthritis in this region and is far more prevalent than rheumatoid arthritis with a previously reported prevalence of $0.7 \%$ in the adult population in the same region in Sweden. ${ }^{20}$
The prevalence of gout in Skåne is lower than corresponding figures in the USA $(3.9 \%)$ but is in line with reports from other western European countries $(1.4 \%$ in the UK and Germany), Australia (1.7\%) and two studies on the prevalence of gout in Sweden. ${ }^{9} 17-19$ 21-28 Several studies have suggested that certain ethnic groups have a higher prevalence of gout compared to those of European ancestry. ${ }^{22} 23$ Genetic factors, higher prevalence of some risk factors such as hyperuricaemia, hypertension and central obesity in some ethnic groups, or special diets may contribute to these disparities. ${ }^{22} 23$ The lowest prevalence was found in Portugal $(0.3 \%)$ and 
Table 4 Sensitivity analysis

\begin{tabular}{|c|c|c|c|c|}
\hline Variable & $\begin{array}{l}\text { Per cent with allopurinol } \\
\text { prescription 2005-2011 } \\
\text { among } 2011 \text { prevalent } \\
\text { cases }\end{array}$ & $95 \% \mathrm{Cl}$ & $\begin{array}{l}\text { Per cent with allopurinol } \\
\text { prescription } 2011 \text { among } \\
2011 \text { incident cases }\end{array}$ & $95 \% \mathrm{Cl}$ \\
\hline All & 73.4 & (72.4 to 74.3 ) & 60.6 & (58.1 to 63.0$)$ \\
\hline \multicolumn{5}{|l|}{ Education (years) } \\
\hline $0-9$ & 73.8 & (72.3 to 75.4$)$ & 59.4 & (55.4 to 63.35$)$ \\
\hline $10-12$ & 72.9 & (71.4 to 74.4$)$ & 59.5 & (55.4 to 63.65$)$ \\
\hline $13-14$ & 72.9 & (69.4 to 76.3$)$ & 64.7 & (57.0 to 72.4 ) \\
\hline $15+$ & 71.6 & (68.2 to 74.9$)$ & 59.3 & (52.0 to 66.7) \\
\hline \multicolumn{5}{|l|}{ Income } \\
\hline Low & 74.1 & (71.1 to 77.1$)$ & 64.5 & (57.5 to 71.6$)$ \\
\hline Middle & 73.9 & (72.7 to 75.1 ) & 61.6 & (58.6 to 64.6$)$ \\
\hline High & 72.3 & (69.3 to 75.3$)$ & 61.34 & (53.9 to 68.8$)$ \\
\hline \multicolumn{5}{|l|}{ Occupation } \\
\hline White collar, high skilled & 71.0 & (68.1 to 74.0$)$ & 60.41 & (53.7 to 67.1) \\
\hline White collar, low skilled & 72.2 & (69.0 to 75.5$)$ & 62.14 & (55.2 to 69.1$)$ \\
\hline Blue collar, high skilled & 76.1 & (72.6 to 79.5$)$ & 51.51 & (43.3 to 59.8$)$ \\
\hline Blue collar, low skilled & 72.9 & (68.5 to 77.2$)$ & 61.71 & (56.3 to 67.1) \\
\hline
\end{tabular}

among adults in France $(0.9 \%) .{ }^{18} 19$ However, the results from the Portuguese study are based on self-reported prevalence of gout and other different methodological issues may explain part of the diverging results. However, influence of genetic, dietary or lifestyle factors cannot be excluded.

Our findings of higher incidence and prevalence of gout in men confirmed results from several previous studies reporting gout being more common in men than in women. ${ }^{1-11}$ Men are known to have higher urate levels compared to women before menopause, which is at least partly due to the uricosuric effect of oestrogen. 3222429 Globally, the lowest prevalence of gout was observed in women aged younger than 45 years and the differences between sexes diminish with increasing age. ${ }^{4}$ Likewise, we here confirm an increasing incidence and prevalence of gout with age. ${ }^{1-13} 1924$ Taken together, these findings additionally support the validity of our definition of gout and the methodological approach we used.

The level of education, income and occupation had an impact on the occurrence of gout in this study. The highest figures were found among individuals with primary school education ( $<9$ years), middle or low income and blue collar occupations. These findings are in line with those reported from three towns in England where gout was more prevalent in a town with the worst socioeconomic status. ${ }^{5}$ In addition, our results are consistent with findings from a cross-sectional study from North Staffordshire in the UK conducted in primary care among individuals $>50$ years where an inadequate income and not attending further education after leaving school were associated with prevalent gout. ${ }^{6}$ Likewise, results from a study on characterisation of patients with severe tophaceous gout in Mexico suggested that low socioeconomic and education levels may contribute to severity of the disease. ${ }^{11}$

In the present study, a person was classified as having gout if having received $\geq 1$ ICD-10 gout diagnosis. Our validity analysis of the gout diagnosis with respect to allopurinol prescription revealed that $59 \%$ of prevalent cases received at least one allopurinol prescription between 2005 and 2011 and $48 \%$ of incident gout cases in 2011 received such prescription during the year 2011. These findings are consistent with results from an observational study of a national Australian general practice population investigating the quality of care of gout which reported allopurinol being prescribed to $57 \%$ of patients with gout. ${ }^{26} \mathrm{~A}$ recently published study examining the eligibility for urate lowering treatment among patients with incident gout in UK in 1997-2000 showed that $44 \%$ of patients fulfilling an indication for urate lowering treatment at first diagnosis were eligible for such treatment, but only a minority had received a prescription. $^{27}$

Sensitivity analysis was performed by calculation of prevalence and incidence using a more stringent definition of gout, that is, any M10 diagnostic code registered at least once by a specialist in internal medicine or rheumatology or at least twice by any other physician. As expected, the analysis showed somewhat lower figures but the same pattern with a much higher prevalence and incidence in men than in women. In addition, a higher percentage of prevalent and incidence cases received at least one allopurinol prescription $(73 \%$ and $61 \%$, respectively). Thus, even using this stringent definition for gout by a substantial proportion did not receive 
urate lowering therapy. This could be explained both by lack of knowledge among primary care providers regarding current treatment guidelines ${ }^{30}$ and by poor compliance among patients with gout (ie, the drug was actually prescribed but not delivered). The latter is likely to be influenced by poor knowledge about the disease and its treatment options among patients with gout. ${ }^{31}$ Apart from deficiencies in patient education, other factors such as socioeconomic status, level of education, age, sex, kidney function and other comorbidity may also affect patient compliance. Our results are in accordance with a systemic review of the literature on adherence to gout treatment reporting that $<50 \%$ of patients with gout in the real-life settings were adherent to their treatment. ${ }^{32}$

This study has the following limitations. First, we studied only the disease diagnosed by a physician and misclassification cannot be ruled out. In a previous validation study with review of clinical records, a positive predictive value of $80 \%$ for fulfilling commonly used classification criteria with our strict definition of gout was found. ${ }^{33}$ This indicates that such a definition identifies the majority of patients with gout when applied to data from a long period of 16 years of healthcare visits. The definition is, however, likely to underestimate the true occurrence and we therefore report results for the more liberal definition. Second, we would not by our methods capture undiagnosed or incorrectly diagnosed cases of gout. Third, data on occupation were missing in about $29 \%$ of prevalent cases and $27 \%$ of incident cases. These data are retrieved from Statistics Sweden and it is known that chronically unemployed or self-employed persons are more likely to have the occupation status missing in the register. ${ }^{34}$

This study also has the following strengths. First, the SHR is population based and thus not prone to selection bias. Second, we used multiple and independent data sources for case identification including the prescribed drugs register in our sensitivity analyses. Third, with up to date 21st century data, we could provide information on the relationship between prevalent and incident gout and socioeconomic status. The occurrence of gout was highest among individuals with more manual labour or middle range income. The clear dose-response relationship between the prevalence and incidence of gout and education level indicates that there is room for improvement through better education, increasing awareness of risk factors and encouraging a healthier lifestyle in particular in groups with a lower socioeconomic level. A change in lifestyle, that is, increased physical activity, has been reported to reduce the risk of mortality in patients with hyperuricaemia. ${ }^{35}$ More interventional studies exploring how diet and lifestyle changes actually alter the disease burden are needed.

\footnotetext{
Author affiliations

${ }^{1}$ Department of Clinical Sciences, Lund, Section for Rheumatology, Lund University, Lund and Skåne University Hospital, Section for Rheumatology in Lund and Malmö, Lund, Sweden
}

${ }^{2}$ Faculty of Medicine, Department of Clinical Sciences Lund, Orthopedics, Clinical Epidemiology Unit, Lund University, Lund, Sweden

${ }^{3}$ Clinical Epidemiology Research and Training Unit, Boston University School of Medicine, Boston, Massachusetts, USA

${ }^{4}$ Department of Rheumatology \& Inflammation Research, Institute of Medicine, The Sahlgrenska Academy, University of Gothenburg, Gothenburg, Sweden

Contributors The study was conceived by ME and MCK. AT retrieved the data and performed the statistical analyses. All authors have interpreted the results. MCK drafted the manuscript, and MH, AT, TS, TN, LJ and ME have revised it for important intellectual content. All coauthors have approved the final version of the manuscript for submission.

Funding This study was supported by grants from the Swedish Rheumatism Association, The Medical Faculty of the University of Lund, Alfred Österlund's Foundation, The Swedish Society of Medicine, Greta and Johan Kock's Foundation, The King Gustaf V Foundation and Lund University Hospital.

Competing interests None declared.

Ethics approval Lund University.

Provenance and peer review Not commissioned; externally peer reviewed.

Data sharing statement No additional data are available.

Open Access This is an Open Access article distributed in accordance with the Creative Commons Attribution Non Commercial (CC BY-NC 4.0) license, which permits others to distribute, remix, adapt, build upon this work noncommercially, and license their derivative works on different terms, provided the original work is properly cited and the use is non-commercial. See: http:// creativecommons.org/licenses/by-nc/4.0/

\section{REFERENCES}

1. Wijnands JM, Viechtbauer W, Thevissen K, et al. Determinants of the prevalence of gout in the general population: a systematic review and meta-regression. Eur J Epidemiol 2015;30:19-33.

2. Kuo CF, Grainge MJ, Mallen C, et al. Rising burden of gout in the UK but continuing suboptimal management: a nationwide population study. Ann Rheum Dis 2015;74:661-7.

3. Kim KY, Ralph Schumacher H, Hunsche $\mathrm{E}$, et al. A literature review of the epidemiology and treatment of acute gout. Clin Ther 2003;25:1593-617.

4. Smith $\mathrm{E}$, Hoy D, Cross M, et al. The global burden of gout: estimates from the Global Burden of Disease 2010 study. Ann Rheum Dis 2014;73:1470-6.

5. Gardner MJ, Power C, Barker DJ, et al. The prevalence of gout in three English towns. Int J Epidemiol 1982;11:71-5.

6. Hayward RA, Rathod T, Roddy E, et al. The association of gout with socioeconomic status in primary care: a cross-sectional observational study. Rheumatology (Oxford, England) 2013;52:2004-8.

7. Gelber AC, Maynard JW, Haywood C Jr. The association of race with gout: a broadly representative inpatient survey. Arthritis Rheum 2010;62(Suppl 10):1565.

8. Wallace K, Riedel A, Joseph-Ridge N, et al. Increasing prevalence of gout and hyperuricemia over 10 years among older adults in a managed care population. J Rheumatol 2004;31:1582-7.

9. Wandell P, Carlsson AC, Ljunggren G. Gout and its comorbidities in the total population of Stockholm. Prev Med 2015;81:387-91.

10. Saag KG, Choi H. Epidemiology, risk factors, and lifestyle modifications for gout. Arthritis Res Ther 2006;8(Suppl 1):S2.

11. Vázquez-Mellado J, Cruz J, Guzmán S, et al. Severe tophaceous gout. Characterization of low socioeconomic level patients from México. Clin Exp Rheumatol 2006;24:233-8.

12. Khanna D, FitzGerald JD, Khanna PP, et al. 2012 American College of Rheumatology Guidelines for management of gout Part I: systematic non-pharmacologic and pharmacologic therapeutic approaches to hyperuricemia. Arthritis Care Res (Hoboken) 2012;64:1431-46.

13. Richette P, Doherty M, Pascual E, et al. 2016 updated EULAR evidence-based recommendations for the management of gout. Ann Rheum Dis 2016;

14. Choi HK, Ford ES, Li C, et al. Prevalence of the metabolic syndrome in patients with gout: the Third National Health and Nutrition Examination Survey. Arthritis Rheum 2007;57:109-15.

15. SSYK 96. Standard för svensk yrkesklassificering. 1996. http://www. scb.se/statistik/_.../OV9999_1998A01_BR_X70ÖP9803.pdf 
16. ISCO. http://www.ilo.org/public/english/bureau/stat/isco/

17. Trifiro G, Morabito P, Cavagna L, et al. Epidemiology of gout and hyperuricaemia in Italy during the years 2005-2009: a nationwide population-based study. Ann Rheum Dis 2013;72:694-700.

18. Reis C, Viana Queiroz M. Prevalence of self-reported rheumatic diseases in a Portuguese population. Acta Reumatol Port 2014;39:54-9.

19. Bardin T, Bouée $S$, Clerson $P$, et al. Prevalence of gout in the adult population of France. Arthritis Care Res (Hoboken) 2016;68:261-6.

20. Englund $M$, Jöud $A$, Geborek P, et al. Prevalence and incidence of rheumatoid arthritis in southern Sweden 2008 and their relation to prescribed biologics. Rheumatology (Oxford) 2010;49:1563-9.

21. Zhu Y, Pandya BJ, Choi HK. Prevalence of gout and hyperuricemia in the US general population: the National Health and Nutrition Examination Survey 2007-2008. Arthritis Rheum 2011;63:3136-41.

22. Singh JA. Racial and gender disparities in patients with gout. Curr Rheumatol Rep 2013;15:307.

23. Kuo C, Grainge MJ, Zhang W, et al. Global epidemiology of gout: prevalence, incidence and risk factors. Nat Rev Rheumato 2015;11:649-62.

24. Annemans L, Spaepen E, Gaskin M, et al. Gout in the UK and Germany: prevalence, comorbidities and management in general practice 2000-2005. Ann Rheum Dis 2008;67:960-6.

25. Robinson PC, Taylor WJ, Merriman TR. Systematic review of the prevalence of gout and hyperuricaemia in Australia. Intern Med $J$ 2012;42:997-1007.

26. Robinson PC, Taylor WJ, Dalbeth N. An observational study of gout prevalence and quality of care in a national Australian general practice population. J Rheumatol 2015;42:1702-7.
27. Kuo $\mathrm{CH}$, Grainge $\mathrm{M}$, Mallen $\mathrm{C}$, et al. Eligibility for and prescription of urate-lowering treatment in patients with incident gout in England. JAMA 2014;312:2684-6.

28. Dehlin M, Drivelegka $\mathrm{P}$, Sigurdardottir V, et al. Incidence and prevalence of gout in western Sweden. Arthritis Res Ther 2016;18:164.

29. Hak AE, Curhan GC, Grodstein F, et al. Menopause, postmenopausal hormone use and risk of incident gout. Ann Rheum Dis 2010;69:1305-9.

30. Spaetgens B, Pustjens T, Scheepers LE, et al. Knowledge, illness perceptions and stated clinical practice behaviour in management of gout: a mixed methods study in general practice. Clin Rheumatol 2016;35:2053-61.

31. Rees F, Jenkins W, Doherty M. Patients with gout adhere to curative treatment if informed appropriately: proof-of-concept observational study. Ann Rheum Dis 2013;72:826-30.

32. De Vera MA, Marcotte G, Rai S, et al. Medication adherence in gout: a systematic review. Arthritis Care Res (Hoboken) 2014;66:1551-9.

33. Dehlin M, Stasinopoulou K, Jacobsson L. Validity of gout diagnosis in Swedish primary and secondary care-a validation study. BMC Musculoskelet Disord 2015;16:149.

34. Statistics Sweden. Statistiska centralbirån. Bakgrundsfakta 2016:1. http://www.scb.se/Statistik/AM/AM9901/_dokument/AM9901_ 1990113_BR_AM76BR1601.pdf

35. Chen $\mathrm{JH}$, Wen $\mathrm{CP}$, Wu SB, et al. Attenuating the mortality risk of high serum uric acid: the role of physical activity underused. Ann Rheum Dis 2015;74:2034-42. 